\title{
Electron beam surface treatment. Part I: surface hardening of AISI D3 tool steel
}

\author{
R.G. Song ${ }^{\mathrm{a}, \mathrm{b}, *}$, K. Zhang ${ }^{\mathrm{a}}$, G.N. Chen ${ }^{\mathrm{a}}$ \\ ${ }^{a}$ Laboratory for Surface Modification, Materials Center, Institute of Mechanics, Chinese Academy of Sciences, Beijing 100080, China \\ ${ }^{\mathrm{b}}$ Institute for Computational Science and Engineering, Ocean University of Qingdao, Shandong 266003, China
}

Received 20 June 2002; accepted 5 August 2002

\begin{abstract}
The effects of electron beam surface hardening treatment on the microstructure and hardness of AISI D3 tool steel have been investigated in this paper. The results showed that the microstructure of the hardened layer consisted of martensite, a dispersion of fine carbides and retained austensite while the transition area mainly consisted of tempered sorbite. Also, the microhardness of the hardened layer on the surface increased dramatically compared to that of base material. Finally, the hardening response of AISI D3 tool steel to electron beam surface treatment is closely related to the scanning speed of the electron beam.
\end{abstract}

(C) 2003 Elsevier Science Ltd. All rights reserved.

Keywords: Electron beam; Surface hardening; Microstructure; AISI D3 tool steel

\section{Introduction}

Recently, the working technology of high power density heat sources such as electron and laser beams has been developed rapidly and applied in welding, cutting and surface hardening [1-10]. Their considerable advantages like the high degree of controllability and automation, low part distortion, capability of very selective and precise treatment are also recognized. Electron beam surface hardening is a process that uses the heat generated by the impingement of an electron beam

\footnotetext{
*Corresponding author. Present address: Research Institute of Biological Resources, National Institute of Advanced Industrial Science and Technology (AIST), 2-17-2-1 Tsukisamu-Higashi, Toyohira-ku, Sapporo 062-8517, Japan. Tel.: +81-11-857-8960; fax: +81-11-857-8984.

E-mail address: song.rg@aist.go.jp (R.G. Song).
}

on the surface of the material to austenitize it, and then the austenitized layers are transformed to martensite because of very rapid conduction of heat into the cold interior of the workpiece. This effect is known as self-quenching and the cooling rates obtained are usually high enough to allow martensite formation, even in steels which have very low hardening ability [11]. In addition, the hardened microstructure obtained is usually finer than that from conventional heat treatment, resulting in hardness and consequently fatigue resistance increasing [12]. Therefore, the electron beam surface hardening technology is one of the most attractive research fields.

The aim of the present research work is to analyse the microstructure and microhardness changes in AISI D3 tool steel occurring as a result of surface hardening by electron beam. 


\section{Experimental}

The material used in this study was a commercial as-quenched AISI D3 tool steel with the following chemical composition (wt \%): C 2.20, Si $0.40, \mathrm{Mn} 0.40, \mathrm{P} 0.03, \mathrm{~S} 0.03$, Cr 12.0, Co 1.00, Fe balance.

The experiments were performed on a $60 \mathrm{~kW}$ moderate voltage electron beam welding machine made in Russia, as shown in Fig. 1. The operation conditions were as follows: $60 \mathrm{kV}$ for accelerating voltage; $5 \mathrm{~mA}$ for beam current; $0.6,1.2$ and $1.8 \mathrm{~m} /$ min, respectively for speed of electron beam gun movement (scanning speed).

Transverse sections of the electron beam traces were cut as specimens for metallographic examination by optical microscopy (OM). All the specimens were ground and polished. Etching was performed using a solution containing $5 \mathrm{ml}$ $\mathrm{HNO}_{3}$ and $95 \mathrm{ml}$ ethanol. Microhardness was measured as a function of depth below the surface for all the electron beam-treated specimens by using a Vickers hardness tester under a load of $0.1 \mathrm{~kg}$.

\section{Results and discussion}

\subsection{Microstructure}

The microstructure of as-quenched AISI D3 tool steel consisted of martensite, carbides and

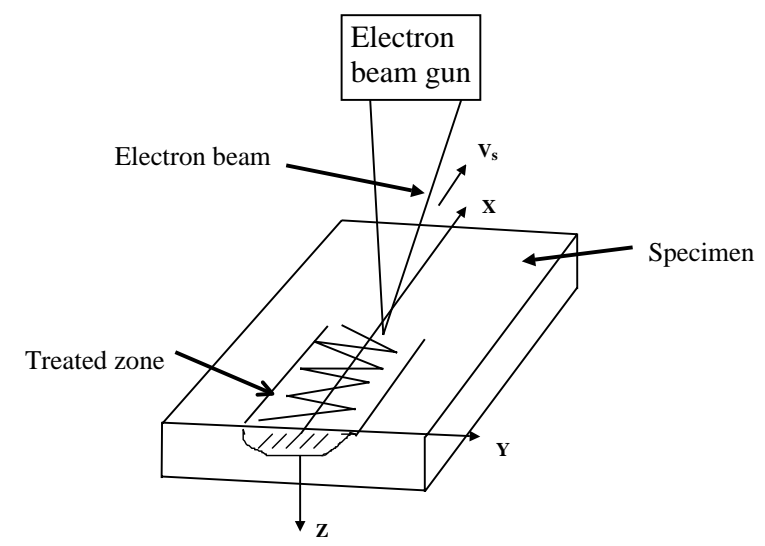

Fig. 1. Schematic diagram of the experimental apparatus. retained austensite, as shown in Fig. 2. In addition, the carbides were very coarse and inhomogeneous.

Fig. 3 shows the transverse section of one of the electron beam-treated specimens $(1.2 \mathrm{~m} / \mathrm{min}$ for scanning speed). It can be seen clearly that there exist three areas. The first one is more lightly etched and forms a hardened layer on the surface of the material. Below this layer there exists a more darkly etched region which extends at greater depths below the surface and forms a very shallow transition layer. These two regions form a zone on the surface, which has clearly undergone a series of phase transformation and is called a 'heat affected zone (HAZ)' here. Finally, the grey area at the bottom is the part of the material which remained unaffected by the process.

The microstructure of hardened layer in Fig. 3 was found to consist of martensite, a dispersion of very fine carbides and retained austensite, as shown in Fig. 4. During electron beam rapid heating process, a large quantity of carbides were dissolved to form austensite with very high content of carbon because the surface of the material was heated directly. Subsequently, martensite, carbides and retained austensite were formed in the rapid cooling process. Compared to the base material, both the grain size and carbides are dramatically refined (see Fig. 2). This is because of rapid heating and subsequent rapid cooling of the material under the electron beam surface hardening condition.

The microstructure of the more darkly etched region in Fig. 3 is shown in Fig. 5, which consists

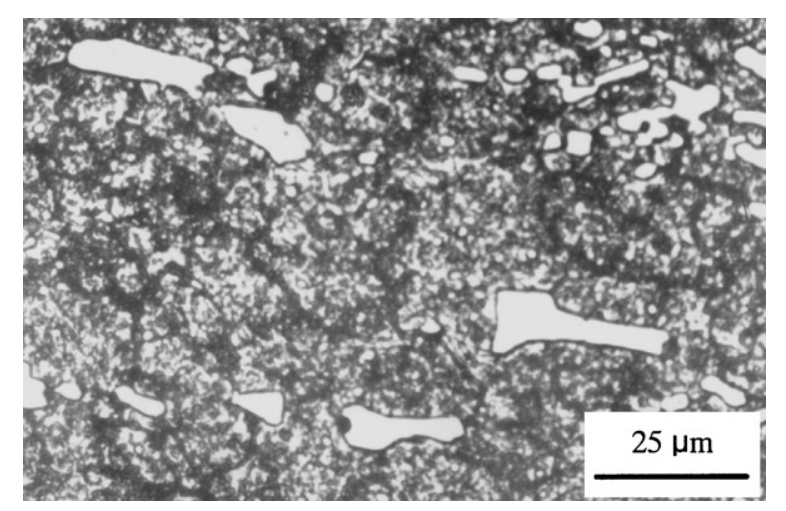

Fig. 2. Microstructure of as-quenched AISI D3 tool steel. 


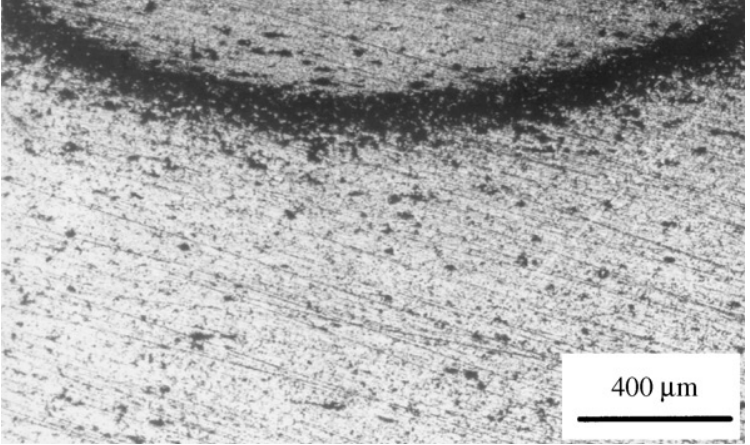

Fig. 3. Transverse section of an electron beam-treated specimen showing the HAZ and the base metal below the surface.

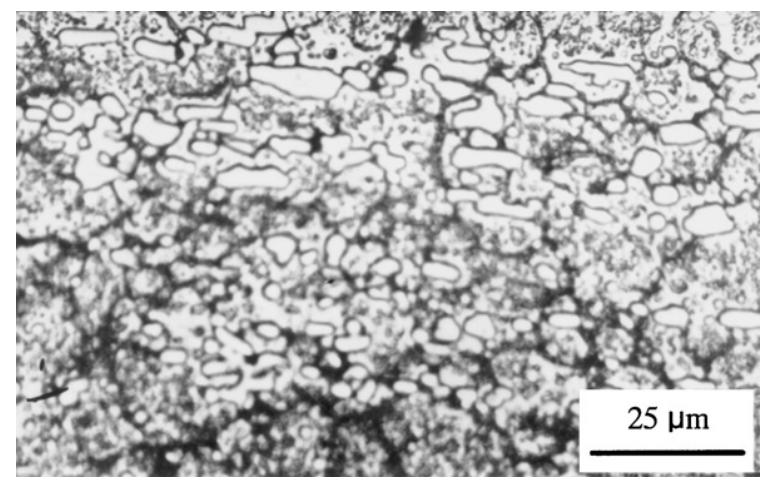

Fig. 4. Microstructure of hardening layer.

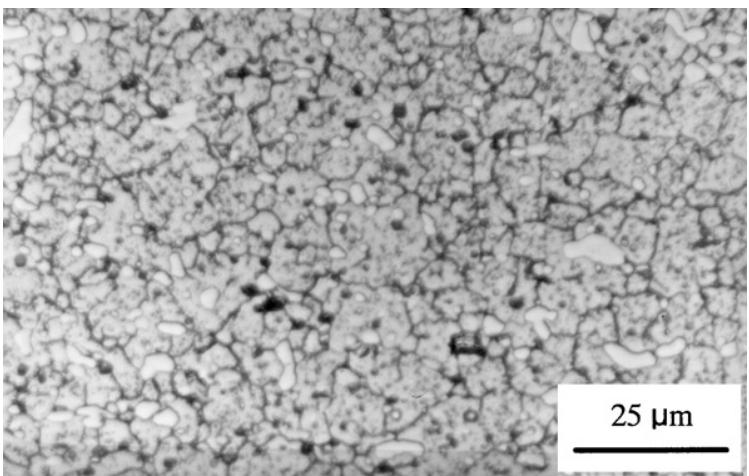

Fig. 5. Microstructure of transition layer.

of tempered sorbite and a small number of carbides. The thermal cycle was inadequate to austenitize this area, but was enough to cause a high-temperature tempering transition since the heating temperature at this area was below $\mathrm{Ac}_{1}$ line.

\subsection{Surface hardening}

Fig. 6 shows the Vickers microhardness profiles of AISI D3 tool steel measured on the crosssection through the centre of single-track runs at different scanning speed. It can be seen that AISI D3 tool steel exhibits remarkable hardening response to electron beam surface hardening. The existence of two areas within the HAZ of the treated specimens is reflected in the corresponding microhardness profiles. The shallow phase transformation hardened layer on the surface had the maximum microhardness, and a gradually decrease of the microhardness occurred within the hardened region, which nevertheless remained higher than the base material. This is attributed to the microstructural refinement following electron beam irradiation and is in agreement with the microstructural observation in that region. An abrupt decrease of the microhardness occurred within the tempered layer and approached the minimum microhardness, which was much lower than the base material. The reason is that the microstructure in this region mainly consisted of tempered sorbite. Finally, the base material microhardness was unaltered at $650 \mathrm{HV}_{0.1}$. It can

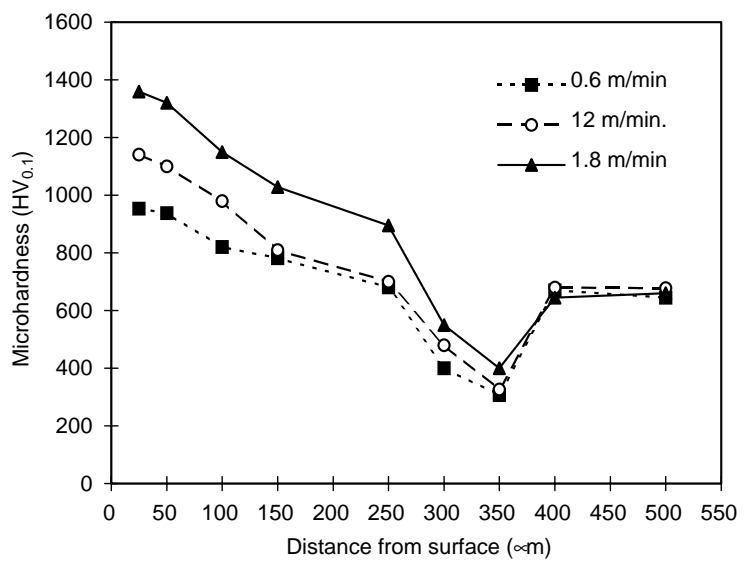

Fig. 6. Microhardness profiles of electron beam-treated specimens at different scanning speeds. 
also be seen that the microhardness of hardened layer increases with increasing the scanning speed of the electron beam. On the one hand, the carbon content of the austensite formed at high temperature decreases with increasing the scanning speed, and then resulting in reducing the content of retained austensite; on the other hand, the grain size decreases while the defect density increases with increasing the scanning speed, hence the microhardness increasing.

\section{Summary}

Surface hardening of AISI D3 tool steel by electron beam exhibits a significant hardening effect on the surface of the material. Hardening is a result of the formation of the HAZ on the surface which comprises of two discrete regions. One is fully austenitized and subsequently formed a hardened layer and another is a transition area between the austenitized region and the base material. The microstructure of the hardened layer consisted of martensite, a dispersion of fine carbides and retained austensite. A high-temperature tempering of the starting microstructure of AISI D3 tool steel took place inside the transition layer resulting in the formation of tempered sorbite, accompanied by an abrupt decrease of microhardness. The microhardness of the har- dened layer increases with increasing the scanning speed of electron beam.

\section{Acknowledgements}

The financial aid of the National Natural Science Foundation of China under grant No. 59836220 is gratefully acknowledged.

\section{References}

[1] Petrov P. Vacuum 1997;48:49.

[2] Dimitrov D, Aprakova M, Valkanov S, Petrov P. Vacuum 1998;49:239.

[3] Kawamura Y, Kagao S, Ohno Y. Mater Trans 2001;42: 2649.

[4] Xiao RS, Ambrosy G, Zuo TC, Hugel H. J Mater Sci Lett 2001;20:2163.

[5] Goswami GL. Laser Eng 2001;11:195.

[6] Markov AB, Rotshtein VP. Nucl Instrum Methods B 1997;132:79.

[7] Li K, Zeng DW, Yung KC, Chan HLW, Choy CL. Mater Chem Phys 2002;75:147.

[8] Friedel KP, Felba J, Pobol I, Wymyslowski A. Vacuum 1996;47:1317.

[9] Muller F, Monaghan J. J Mater Process Technol 2001; 118:278.

[10] Choo SH, Lee S, Golkovski MG. Mater Sci Eng A 2000; 293:56.

[11] Tauqir A, Zaigham H, Hashmi FH, Khan AQ. J Mater Sci 1997;32:465.

[12] Hwang JR, Fung CP. Surf Coat Technol 1996;80:271. 